\title{
Hidden Hearing Loss: A Disorder with Multiple Etiologies and Mechanisms
}

\author{
David C. Kohrman, ${ }^{1,4}$ Guoqiang Wan, ${ }^{2,3,4}$ Luis Cassinotti, ${ }^{1,4}$ and Gabriel Corfas ${ }^{1}$ \\ ${ }^{1}$ Kresge Hearing Research Institute, Department of Otolaryngology-Head and Neck Surgery, University \\ of Michigan, Ann Arbor, Michigan 48109 \\ ${ }^{2}$ MOE Key Laboratory of Model Animals for Disease Study, Model Animal Research Center of Nanjing \\ University, Nanjing 210061, Jiangsu Province, China \\ ${ }^{3}$ Institute for Brain Sciences, Nanjing University, Nanjing 210061, Jiangsu Province, China \\ Correspondence: corfas@med.umich.edu
}

Hidden hearing loss $(\mathrm{HHL})$, a recently described auditory disorder, has been proposed to affect auditory neural processing and hearing acuity in subjects with normal audiometric thresholds, particularly in noisy environments. In contrast to central auditory processing disorders, $\mathrm{HHL}$ is caused by defects in the cochlea, the peripheral auditory organ. Noise exposure, aging, ototoxic drugs, and peripheral neuropathies are some of the known risk factors for HHL. Our knowledge of the causes and mechanisms of HHL are based primarily on animal models. However, recent clinical studies have also shed light on the etiology and prevalence of this cochlear disorder and how it may affect auditory perception in humans. Here, we review the current knowledge regarding the causes and cellular mechanisms of $\mathrm{HHL}$, summarize information on available noninvasive tests for differential diagnosis, and discuss potential therapeutic approaches for treatment of $\mathrm{HHL}$.

Sensorineural hearing loss affects more than S320 million people worldwide (Olusanya et al. 2014) and has traditionally been diagnosed clinically by the presence of permanently elevated auditory thresholds. This type of hearing loss is caused by the dysfunction or degeneration of inner hair cells (IHCs), outer hair cells (OHCs), and/or spiral ganglion neurons (SGNs) in the cochlea. Together, these cells are responsible for detection, encoding, and transmission of acoustic information to the central auditory circuits. Many human subjects, however, show normal auditory sensitivity (auditory thresholds), yet have significant perceptual difficulties, including understanding speech in noisy backgrounds (Halpin et al. 1994; Gordon-Salant 2005; Grose and Mamo 2010; Ruggles et al. 2011; Bharadwaj et al. 2015). Such perceptual dysfunction has often been termed "auditory processing disorder," and defects in central auditory pathways have been thought to play a key role (Chermak and Musiek 1997). However, recent studies provide evidence that changes in the peripheral auditory system (the cochlea) induced by noise, drugs, peripheral neuropathy, or aging can also alter the neural sound-evoked output of the auditory

${ }^{4}$ These authors contributed equally to this work.

Editors: Guy P. Richardson and Christine Petit

Additional Perspectives on Function and Dysfunction of the Cochlea available at www.perspectivesinmedicine.org

Copyright (C) 2020 Cold Spring Harbor Laboratory Press; all rights reserved; doi: 10.1101/cshperspect.a035493

Cite this article as Cold Spring Harb Perspect Med 2020;10:a035493 
D.C. Kohrman et al.

nerve $(\mathrm{AN})$ independently of hair cell loss and changes in hearing thresholds. This form of hearing loss has been referred to as "hidden hearing loss" (HHL) to reflect that the dysfunction is not revealed by standard tests of auditory thresholds (audiometric test; see Box 1) (Schaette and McAlpine 2011). Based on recent surveys, the prevalence of this type of dysfunction as described by subjects with self-reported hearing difficulties despite having normal hearing thresholds has been estimated at $12 \%-15 \%$ (Tremblay et al. 2015; Spankovich et al. 2018).
The auditory defects associated with HHL have been shown in animal models by detection of changes in neural responses to sounds with intensities above hearing thresholds (suprathreshold sounds) in the absence of changes in sensitivity (threshold shifts). Early studies in mice indicated that moderate noise exposures that induce temporary threshold shifts (TTS) do not induce hair cell death, but rather result in decreased responses to suprathreshold sounds that persist after thresholds recover. The observation that the decreased amplitude in the response

\section{BOX 1. AUDIOMETRIC TESTS}

Audiometric threshold testing in human subjects: a psychophysical test that evaluates the sensitivity of hearing perception, typically in response to pure tones with discrete frequencies (250 to 8000 $\mathrm{Hz}$ ) that span most of the human audible range. Sensitivity is expressed as a detection threshold on a logarithmic scale and is measured in decibels $(\mathrm{dB})$ relative to a reference sound pressure level $(\mathrm{SPL})$.

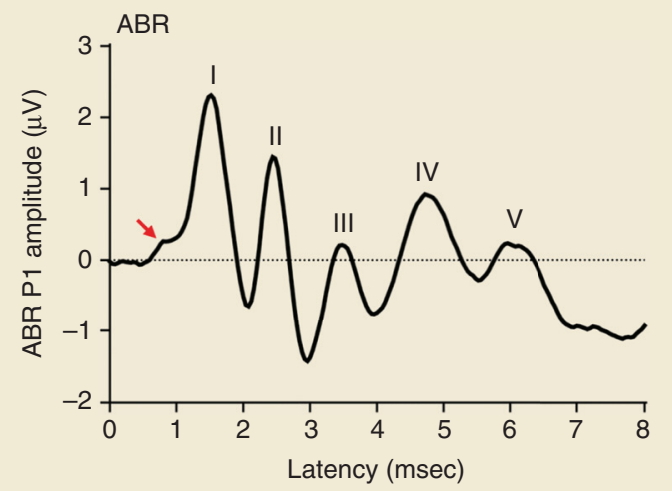

Auditory brainstem response (ABR): a far-field response detected by head-mounted electrodes that measures the synchronous electrical activity of the auditory system evoked by transient sounds. A typical ABR waveform obtained from a mouse in response to a pure tone is shown above, and consists of five major peaks, with peak I corresponding to activity generated by the auditory nerve within $2 \mathrm{msec}$ following the sound stimulus, and the later peaks II through V corresponding to activity generated by neurons in successive nuclei of the auditory hindbrain. The small minor peak that occurs just before peak I (red arrow) is the summating potential (SP), which is generated mainly by activity of inner hair cells in the cochlea. The magnitude of peak I amplitudes correlates with the number and synchronous firing rate of the SGN fibers. Thresholds are determined by the lowest intensity of sound that will produce a recognizable waveform.

Compound action potential (CAP): a near-field response detected by electrodes at the cochlear round window in animals or at the tympanic membrane (eardrum; known as "electrocochleography") in humans. Like in the ABR, this response measures the synchronous activity of the auditory nerve that is evoked by transient sounds and the same peaks can be detected.

Distortion product otoacoustic emission (DPOAE): a sound produced by the cochlea in response to presentation of two simultaneous sounds, measured using a sensitive microphone placed in the ear canal. Production of this emitted sound depends on the amplification activity of outer hair cells in the cochlea. 
to suprathreshold sounds correlates with the loss of a subset of synaptic connections between IHCs and AN fibers in the cochlea led to the notion that noise-induced synaptopathy causes HHL (Kujawa and Liberman 2009). The strong evidence for this HHL mechanism resulted in the terms synaptopathy and HHL often being used interchangeably. However, more recent findings indicate that other causes of HHL exist, including cochlear demyelination (Wan and Corfas 2017; Choi et al. 2018) and possibly mild or persistent hair cell dysfunction (Hoben et al. 2017; Mulders et al. 2018). Here, we summarize the current knowledge of HHL and discuss the diverse mechanisms that lead to the development of this pathology in animal models and humans. In addition, we review the different diagnostic tools and potential treatments for HHL.

\section{CAUSES OF HIDDEN HEARING LOSS}

\section{Noise Exposure}

Numerous studies in mice (Kujawa and Liberman 2009; Shi et al. 2015), rats (Lobarinas et al. 2017), and guinea pigs (Lin et al. 2011; Liu et al. 2012; Shi et al. 2013, 2016; Song et al. 2016) showed that moderate noise exposure induces HHL. These studies found that moderate noise exposures (e.g., $100 \mathrm{~dB}$ sound pressure level [SPL] for 2 hours in mice) produce acute but temporary shifts in auditory thresholds $(A B R$, CAP, and DPOAE, see Box 1) that recover within days or weeks (for review, see Hickox et al. 2017). These TTSs occur without hair cell loss. However, even after threshold recovery, cochlear responses to suprathreshold sound levels are significantly altered; that is, the amplitude of the first peak of the ABR waveform (ABR peak I) is reduced, consistent with a decreased number of AN fibers activated by the sound, and/or a decrease in their firing rate or synchrony. Although most early studies evaluated the effects of continuous noise, recent reports indicate that a single blast exposure may also result in HHL both in animals (Niwa et al. 2016; Hickman et al. 2018) and in humans (Bressler et al. 2017). The reduced neural responses associated with noise-induced HHL are expected to alter the coding of temporal and intensity features of suprathreshold sounds and to reduce the ability to perceive sounds in complex listening environments, such as those with background noise. The latter has been tested in rats with HHL following exposure to 109-dB SPL octave band noise, which resulted in TTS and permanent reductions in ABR peak I amplitudes (Lobarinas et al. 2017). Although thresholds recovered within 2 weeks, behavioral testing of exposed rats showed a poorer performance in a test of hearing in background noise.

In humans, the neural coding problems associated with HHL are expected to produce deficits in speech discrimination and intelligibility, especially in noisy environments (Kujawa and Liberman 2015; Wan and Corfas 2015). A number of studies are consistent with this prediction, suggesting that individuals who have experienced exposures to loud noise have greater difficulties in complex listening tasks despite near normal audiological thresholds. For example, subjects with higher reported noise exposures than controls with similar thresholds showed significant deficits in word recognition (Alvord 1983) and in accurate speech and sound detection in noisy background environments (Kujala et al. 2004; Kumar et al. 2012; Liberman et al. 2016). Furthermore, young adults with a history of exposure to loud recreational noise have problems in discrimination of bursts of narrowband sounds presented at low levels relative to those with less exposure (Stone et al. 2008). Effects of noise exposure have been reported for ABR and electrocochleogram peak I amplitudes in response to suprathreshold stimuli (Stamper and Johnson 2015; Liberman et al. 2016; Valderrama et al.2018). Finally, a variety of physiological and perceptual measures were used by Bharadwaj et al. (2015) to investigate a group of young adult subjects (21-39 years old) with normal hearing sensitivity to determine potential relationships between coding of suprathreshold responses and perception of complex auditory stimuli. Although this study identified only "marginally significant" correlations between reported noise history and several measures of temporal coding, better temporal coding metrics were strongly associated with better perception of "competing" speech and to sounds that differ 
D.C. Kohrman et al.

in their binaural timing characteristics. Together, these studies highlight the importance of accurate neural coding of suprathreshold sounds, independent of auditory sensitivity, for performance in complex listening environments, and suggest that accumulated noise exposures can degrade these abilities.

However, several recent studies have failed to find significant correlations among prior noise exposure, electrophysiological measures associated with HHL and perceptual hearing ability (Kluk et al. 2016; Fulbright et al. 2017; Grinn et al. 2017; Prendergast et al. 2017a,b; Guest et al. 2018). Additionally, studies in which small negative correlations were shown between reported noise exposure and ABR peak I amplitudes, often failed to identify a clear relationship with expected perceptual dysfunction (Grose et al. 2017; Valderrama et al. 2018). Many factors may underlie the discordant studies relating noise and HHL, including inaccuracies in self-reporting of lifetime noise exposure, potential confounding effects of age and central auditory system compensation mechanisms, and the effects of different underlying mechanisms on physiological and behavioral measures of hearing.

\section{Aging}

The ability to understand speech in noisy environments decreases with age even in subjects with normal auditory thresholds in response to sounds up to at least $8 \mathrm{kHz}$ (Dubno et al. 1984; Frisina and Frisina 1997; Pichora-Fuller and Souza 2003; Rajan and Cainer 2008). Likewise, aging subjects show declines in neural coding of the temporal features of sound that are likely important for speech perception in noise, and such deficits can also occur independently from increases in thresholds (Clinard and Tremblay 2013; Marmel et al. 2013; King et al. 2014). Decreases in the amplitudes of ABR peak I in aging human subjects are consistent with a cochlear neuropathy and could underlie these temporal processing defects (Konrad-Martin et al. 2012). Similar declines $(>50 \%)$ across the life span in $A B R$ peak I amplitudes have also been shown in mice (Sergeyenko et al. 2013; Muniak et al. 2018). Although these mice show a gradual in- crease in auditory thresholds over the course of their life span, this appears to be driven largely by $\mathrm{OHC}$ loss at later ages. The decreases in ABR peak I amplitudes in response to suprathreshold stimuli also progress over time but follow an earlier trajectory that parallels the pattern of IHC synapse loss (Sergeyenko et al. 2013), consistent with synaptopathy being a key contributor to age-related HHL in mice. Furthermore, Liberman and colleagues reported that a single noise exposure that causes TTS and HHL in young adult mice (4 months of age) significantly accelerates the rate of age-related overt hearing loss, including ABR threshold elevations and OHC loss. This data indicates that a single exposure to moderate noise levels (TTS type) early in life predisposes to an accelerated, progressive hearing loss across the life span (Kujawa and Liberman 2009; Fernandez et al. 2015).

\section{Peripheral Neuropathy}

A number of peripheral neuropathies can directly affect AN function and SGN survival (Rance and Starr 2015). The hearing loss associated with these disorders is often termed "auditory neuropathy," as defined by intact $\mathrm{OHC}$ function together with altered ABRs. Although peripheral neuropathies often result in relatively large effects on AN function and thereby alter ABR thresholds, some patients show normal hearing sensitivity yet have significant perceptual difficulties, for example, in Guillain-Barré syndrome (GBS) and Charcot-Marie-Tooth (CMT) disease. GBS is caused by transient damage to peripheral myelinating Schwann cells (Kuwabara and Yuki 2013). Intriguingly, in GBS patients who suffered acute hearing loss, although hearing threshold gradually recovered, the latency of their ABR waveforms was persistently increased, indicative of HHL (Takazawa et al. 2012). CMT is an inherited, progressive peripheral neuropathy that affects both motor and sensory nerves and is genetically heterogenous (Rossor et al. 2013). Clinical evaluations of motor nerve conduction velocities have been used to classify CMT as either demyelinating (type 1) or axonal (type 2). Many individuals with CMT show classic auditory neuropathy 
characterized by normal OHC function but significant decreases in hearing sensitivity, often with ABR latency alterations (Rance 2005). Nonetheless, evaluation of a cohort of children genetically diagnosed with CMT1 or CMT2 showed that a majority of cases exhibited decreased speech understanding and altered temporal processing despite normal or near normal auditory thresholds (Rance et al. 2012). Similarly, a recent study of individuals diagnosed with CMT1A, the most common form of CMT that is associated with copy number variation of the gene encoding Peripheral Myelin Protein 22 (PMP22), provided additional evidence of HHL in this patient population (Choi et al. 2018). A cohort of 43 CMT1A patients ranging in age from 14 to 64 years showed normal pure tone threshold averages at a range of frequencies $(250 \mathrm{~Hz}$ to $8 \mathrm{kHz}$ ), and their speech perception scores in quiet matched those of a group of ageand sex-matched controls. However, the mean score for speech perception in noise was reduced in the CMT1A patients, and their abilities to detect stimuli that require temporal and spectral acuity were also decreased. Early evaluation of auditory function in mouse models of CMT1 indicated a combination of elements of both HHL and auditory sensitivity defects associated with decreased AN myelination, including loss of AN proximal fibers and SGNs along with small increases in ABR thresholds and large decreases in peak I amplitudes in response to suprathreshold sounds (Zhou et al. 1995). Therefore, it is likely that HHL is an integral part of CMT pathology, whereas the degree of AN demyelination and SGN death dictates whether threshold shifts will be detected in audiometric tests.

\section{Ototoxicity}

High doses of aminoglycoside antibiotics such as gentamicin have long been known to cause auditory threshold shifts because of hair cell toxicity (Schacht et al. 2012). Interestingly, this type of exposure also has been shown to induce acute swelling of SGN terminal dendrites (Duan et al. 2000), similar to the morphology associated with excitotoxic damage of IHC synapses by noise exposure (Ruel et al. 2007). Most relevant to the focus of this review, doses of aminoglycosides that spare hair cells also have been linked to loss of IHC synapses, although the precise relationship to HHL and temporal processing in this case has not yet been determined. Liu et al. (2015) reported that systemic delivery of low dose gentamycin to mice for 2 weeks results in a temporary decrease in IHC synapse numbers, which partially recovered following cessation of the drug and suggested that synapses can be restored under these conditions. Oishi et al. (2015) found that a single middle ear administration of low amounts of gentamycin into mice results in small threshold increases associated with both synapse loss and SGN loss while sparing hair cells. This effect was observed although only in XBP-1 mutant mice with compromised stress responses but not in wild-type mice. Additional studies in mice have also implicated systemic gentamycin in acute losses of SGN dendrites (Ruan et al. 2014) or IHC synapses (Hong et al. 2018) at doses that did not cause substantial hair cell loss. In the latter study, synapse loss was accompanied by both small threshold shifts and large declines in ABR peak I amplitudes (Hong et al. 2018).

\section{MECHANISMS OF HIDDEN HEARING LOSS}

\section{Cochlear Synaptopathy}

The best documented mechanism for HHL is the degeneration of cochlear ribbon synapses without hair cell loss and SGNs (i.e., cochlear synaptopathy) (Fig. 1). These synapses, located at the basal end of IHCs, consist of a presynaptic specialization known as a "ribbon" that contains neurotransmitter vesicles and the release apparatus, as well as a postsynaptic zone in the nerve terminal with AMPA glutamate receptors (Reijntjes and Pyott 2016). The association between HHL and the loss of IHC-SGN synapses was first noted in studies of the effects of moderate noise in mice by Kujawa and Liberman (2009). These TTS exposures resulted in no loss of hair cells and full recovery of auditory thresholds but a permanent decline in AN responses to suprathreshold sounds as measured by the amplitudes of ABR peak I, or of CAPs measured at the cochlear round window. The 
D.C. Kohrman et al.

A

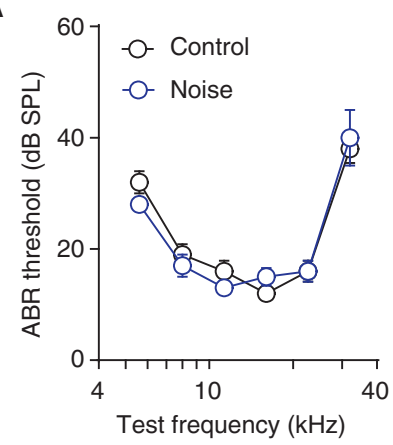

B

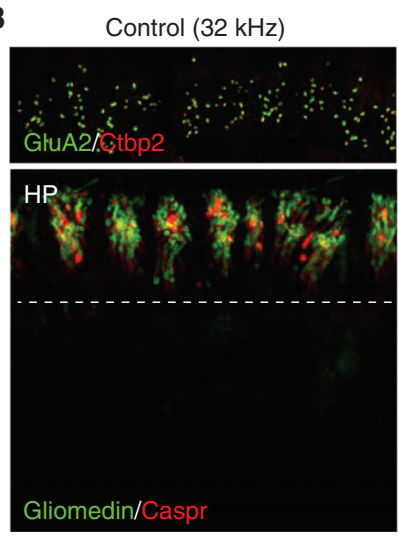

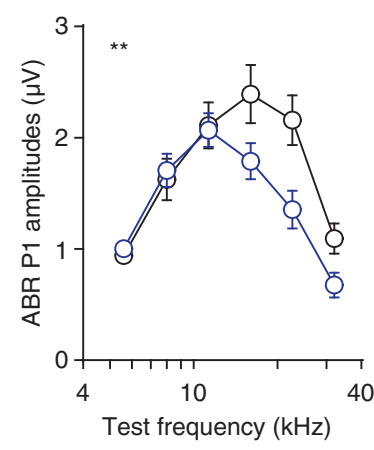

Noise $(32 \mathrm{kHz})$
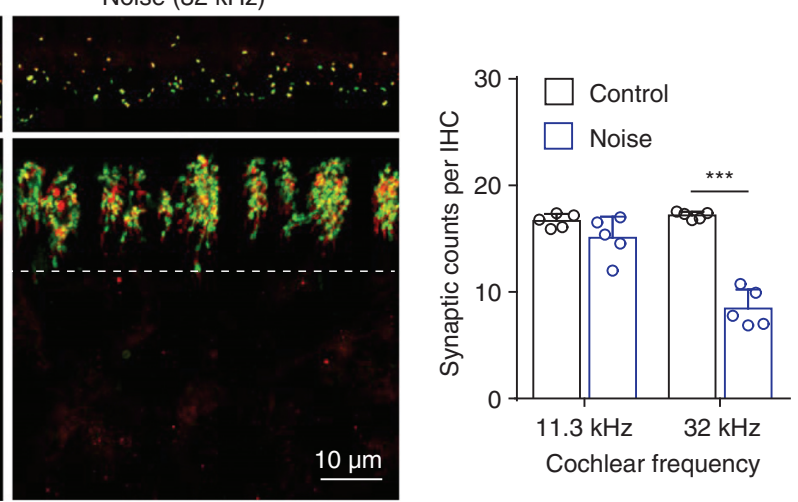

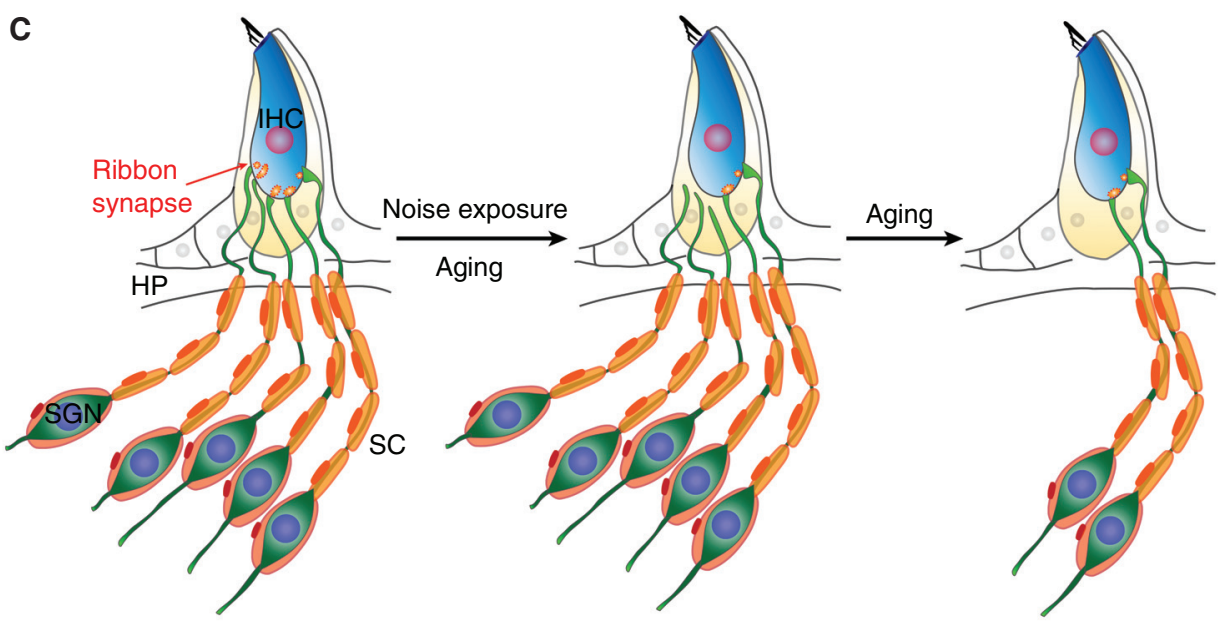

Figure 1. Hidden hearing loss (HHL) caused by cochlear synaptopathy. ( $A$ ) Auditory brainstem response (ABR) recordings of control mice and mice 2 weeks after noise exposure (8-16 kHz, $100 \mathrm{~dB}$ sound pressure level [SPL], 2 hours). Noise exposure causes reduction of ABR peak I (P1) amplitudes without changes in threshold and latency. ( $B$ ) The same HHL-causing noise exposure used in $A$ results in inner hair cell (IHC) ribbon synapse loss in the base of the cochlea (e.g., $32 \mathrm{kHz}$ region of the cochlea) but does not affect node of Ranvier structures. (C) Model for HHL caused by cochlear synaptopathy. Noise exposure or aging result in synaptic degeneration of low spontaneous rate (SR) AN fibers, which over time progresses to spiral ganglion neuron (SGN) loss. (Panels $A$ and $B$ modified from Wan and Corfas 2017; courtesy of Creative Commons Attribution 4.0 International License.) 
suprathreshold changes were associated with permanent decreases of up to $50 \%$ of the number of presynaptic ribbon synapses as determined by immunostaining for RIBEYE/CtBP2, a component of the presynaptic ribbon. The decline in synapse numbers in this study was proportional to the relative decreases in suprathreshold responses and was found in basal, high-frequency regions of the cochlea that showed functional deficits. It has been speculated that the initiator of synapse damage and deafferentation may be glutamate-mediated excitotoxicity, which induces swelling of the SGN terminal fibers under IHC soon after damaging noise exposures (Ruel et al. 2007; Liberman and Kujawa 2017).

Similar characteristics of synaptopathy have also been shown in several mouse strains, and in rats, guinea pigs, chinchillas, and rhesus monkeys following TTS-type noise (Hickox et al. 2017; Valero et al. 2017). Not surprisingly, exposure to higher intensity noise that induces permanent threshold shifts (PTSs) associated with extensive OHC death and moderate IHC losses results in an even greater decrease in synapse numbers on surviving IHC relative to TTS noise exposure (Valero et al. 2017). Although evidence of TTS noise effects in mouse supports the permanence of the synaptic loss (Fernandez et al 2015), most studies in other species have not examined longer-term effects of noise on synapse integrity. Several recent studies of guinea pigs exposed to less intense noise levels and evaluated at later time points suggest, however, that some synaptic repair may be possible following the initial damage (Liu et al. 2012; Shi et al. 2013, 2015, 2016; Song et al. 2016). As most studies used immunostainings of synaptic markers as indicators of synaptic integrity, it remains to be determined whether synaptic loss and regeneration involves structural alterations and/or dynamic changes in marker expression.

Most of the synapse loss following TTS noise exposure occurs within hours of the noise and appears to preferentially occur in synapses associated with AN fibers that have low spontaneous rate firing activity (low SR) and high threshold response properties (Furman et al. 2013; Liberman and Liberman 2015). These low SR fibers also show larger dynamic ranges (Schalk and
Sachs 1980), preserve information concerning stimulus timing and amplitude modulation (AM) more efficiently (Joris et al. 1994; Rhode and Greenberg 1994; Frisina et al. 1996), and are less vulnerable to masking in background noise than high SR fibers (Costalupes et al. 1984). Preferential loss of low SR fibers would therefore be consistent with the decreased responses to suprathreshold sounds and auditory acuity in complex listening environments that have been associated with the synaptic damage from TTS noise exposures. The synapses associated with high SR fibers that remain following TTS noise retain normal threshold and frequency tuning characteristics and presumably explain the recovery of normal auditory thresholds (Furman et al. 2013).

A strong correlation between synapse loss and reduced suprathreshold responses was found in mice during aging, supporting the notion that synaptopathy is a key contributor to progressive auditory neuropathy and HHL in the absence of noise overexposure (Sergeyenko et al. 2013). In addition, SGN loss in aging mice occurred at approximately the same rate as the synaptopathy but with several months delay, suggesting that synapse loss predisposes neurons to degeneration (Sergeyenko et al. 2013). Indeed, mice with noise-induced synaptopathy in the cochlear base at early ages show higher degrees of SGN loss later in life than nonexposed mice, and this occurs in the same cochlear regions affected by the exposure (Fernandez et al. 2015). Electrophysiological studies in aging gerbils indicate that, as in TTS noise-exposed mice, low SR AN fibers are preferentially lost, and supports the idea that loss of such fibers could give rise to the suprathreshold response and temporal coding deficits associated with HHL during aging (Schmiedt et al. 1996).

SGN counts of a large set of human cochleae from a range of subject ages with relatively intact hair cell numbers and no evidence of otologic disease indicated a similar rate of SGN loss across the life span (Makary et al. 2011). In addition, immunostaining for IHC ribbon synapses and peripheral AN fibers in separate sets of human cochleae with relatively intact IHC populations suggested a progressive deafferentation that proceeds faster than the rate of SGN 
D.C. Kohrman et al.

loss in the Makary et al. study (Viana et al. 2015; $\mathrm{Wu}$ et al. 2018). These findings are similar to those obtained in aging mice, suggesting that synaptopathy in humans may also predispose SGN to degeneration.

\section{Demyelination}

Proper development and maintenance of $\mathrm{AN}$ myelination by Schwann cells is critical for auditory processing fidelity and defects in myelination have been implicated in hearing loss in both humans and animal model systems (Long et al. 2018). Schwann cells are critical for the formation of nodes of Ranvier, the specialized regions along myelinated fibers at which voltage-gated sodium and potassium channels are clustered for regeneration of action potentials and the fast, synchronized transmission of electrical signals (Rasband and Peles 2015). In addition to demyelinating disorders such as CMT1 that clearly affect temporal processing in $\mathrm{AN}$, other risk factors for HHL such as noise and aging have also been associated with myelin dysfunction. Exposure of rats to loud noise has been associated with thinning of myelin surrounding $\mathrm{AN}$ and also changes to paranodal myelin regions that are important for function of the nodes of Ranvier (Tagoe et al. 2014). Although this noise level produced increases in threshold shifts, reductions in ABR peak I amplitudes and increases in latency were also observed. Similar myelin defects and changes to suprathreshold stimuli have also been observed in mice exposed to noises that produce a combined TTS-PTS (Panganiban et al. 2018). Other studies based on electron microscopy reported thinning and degeneration of myelin sheaths in the AN of aging mice, which correlated with decreases in myelin basic protein (MBP) levels and declines in ABR peak I amplitudes (Xing et al. 2012). Age-associated decreases in MBP levels were also noted in AN from a set of human temporal bone specimens (Xing et al. 2012), suggesting myelin loss could contribute to the temporal processing abnormalities described in aging humans, including increases in response latency and dyssynchrony (Plack et al. 2014; Harris and Dubno 2017).
Recently, Wan and Corfas (2017) reported that transient demyelination also results in HHL (Fig. 2). This study showed that ablation of Schwann cells via genetic means in adult animals causes a near total loss of AN myelin within 1 week. Remarkably, this loss does not alter auditory thresholds, yet induces a permanent HHL, that is, suprathreshold ABR peak I amplitudes are significantly decreased. In contrast to the HHL produced by noise exposure, ABR peak I latency was also increased by demyelination. These alterations persist even after complete AN remyelination through proliferation and differentiation of new Schwann cell precursors. Although no changes in IHC-SGN synapses were observed following the acute demyelination, immunostaining studies showed a permanent defect in the nodal structures closest to the IHCs, known as heminodes. Electrophysiological and immunostaining studies showed that the heminode is the action potential generator in AN (Hossain et al. 2005; Rutherford et al. 2012; Kim and Rutherford 2016). Together, these observations indicate that heminode disruption is likely to be the basis for the HHL observed following transient demyelination (Wan and Corfas 2017). The temporary hearing sensitivity deficits, together with persistently increased ABR latencies observed in some humans with transient demyelination caused by GBS, appear to match the phenotype of this mouse model (Takazawa et al. 2012).

\section{Hair Cell Dysfunction}

Two recent studies suggested that noise-induced hair cell dysfunction could also contribute to HHL. Mulders et al. (2018) reported that guinea pigs with noise-induced HHL also have persistent reductions in summating potential (SP) amplitudes. As the SP reflects the sound-induced IHC receptor current (Zheng et al. 1997), the investigators suggested that long-lasting changes in IHC electrophysiological function might contribute to HHL. However, this finding contradicts other studies in which the SP was reported to be stable after noise exposure in HHL mouse models (Kujawa and Liberman 2009) and during aging (Sergeyenko et al. 2013). The second study involved human listeners and suggested OHC 
A

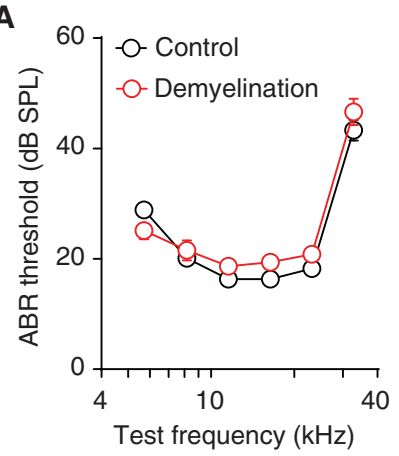

B
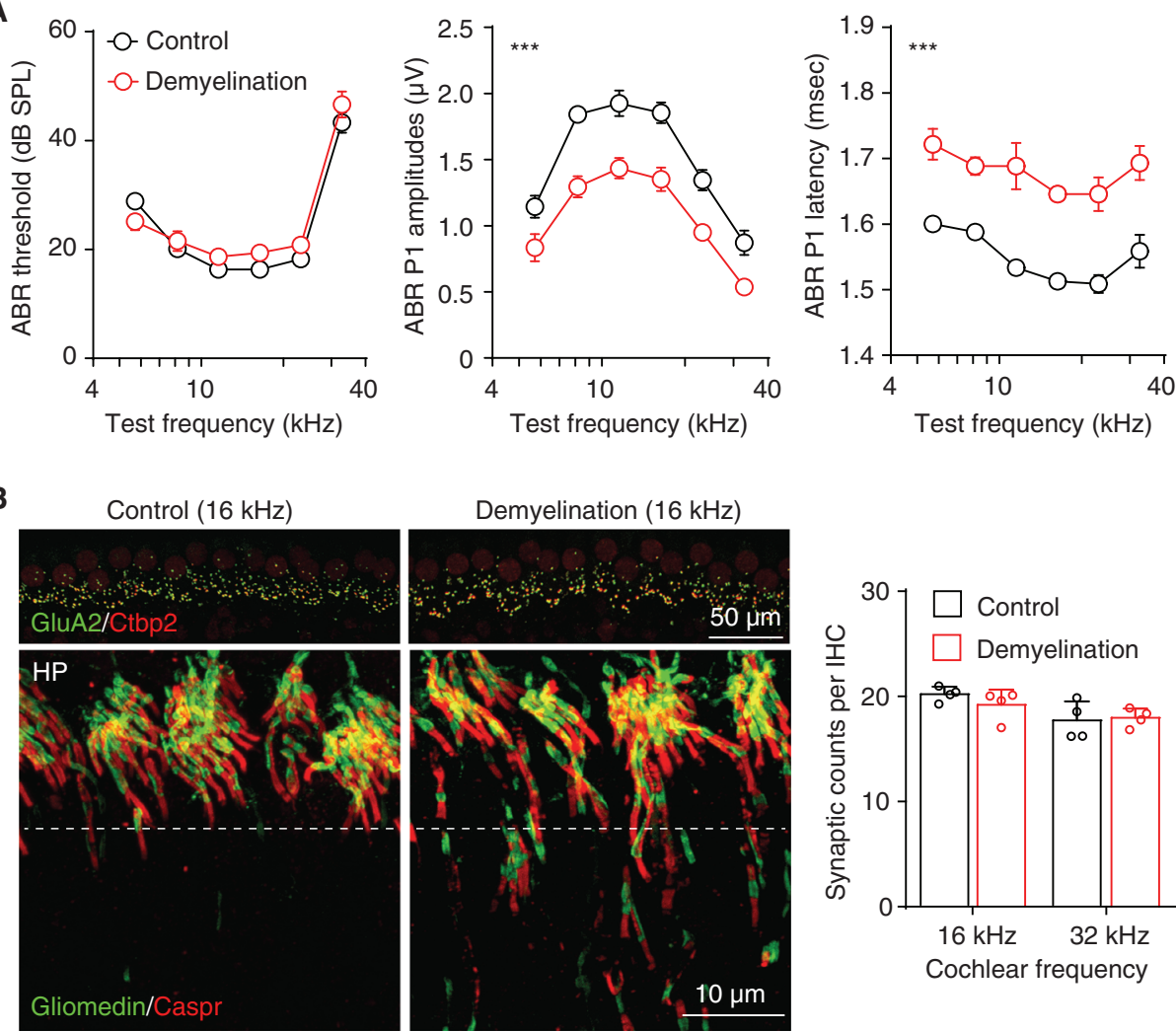

\section{C}
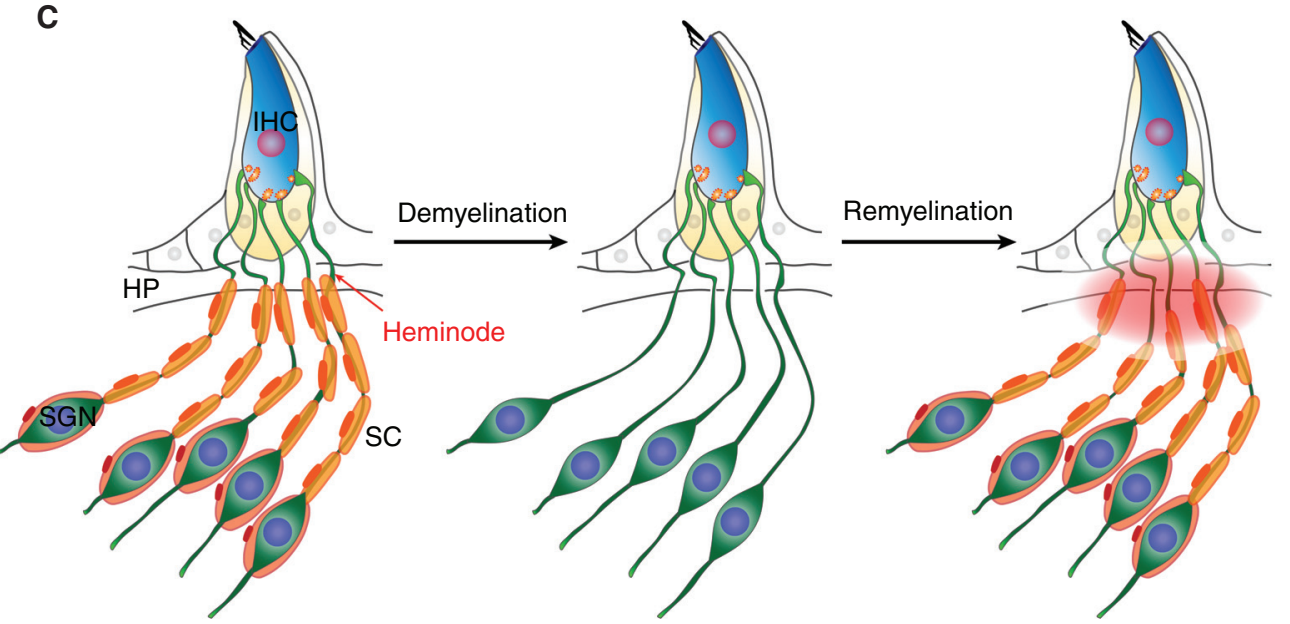

Figure 2. Hidden hearing loss (HHL) caused by cochlear demyelination. (A) Auditory brainstem response (ABR) recordings from control mice and mice 4 months after transient demyelination caused by Schwann cell ablation. Mice present with clear signs of HHL, that is, ABR P1 amplitude reduction, latency increase, but no threshold elevation. (B) Demyelination causes persistent heminode pathology without loss of ribbon synapses. (C) Model for HHL caused by transient demyelination. After auditory nerve (AN) demyelination, remyelination takes place but the heminode structures do not recover. (Panels $A$ and $B$ modified from Wan and Corfas 2017; courtesy of Creative Commons Attribution 4.0 International License.) 
D.C. Kohrman et al.

involvement in HHL (Hoben et al. 2017). This group reported correlations among very mild threshold elevations, altered DPOAEs, and difficulties in speech in noise. Importantly, they found no correlation of those variables with CAP amplitudes. Based on these observations, the investigators hypothesized that loss of $\mathrm{OHCs}$ results in sound-induced deflection of a broader region of the basilar membrane, thereby recruiting a larger population of AN fibers and compensating for decreased cochlear amplifier function at low sound levels (i.e., normal CAP thresholds), but that this process leads to altered temporal acuity and compromises speech understanding in noisy backgrounds (Hoben et al. 2017). Further exploration of the contribution of hair cell dysfunction to HHL is necessary.

\section{DIAGNOSIS OF HIDDEN HEARING LOSS}

Although HHL can be effectively studied in animal models with a combination of invasive physiological and histological tests, this is not possible in human subjects. Therefore, specific, sensitive, and reliable noninvasive diagnostic tests are essential. Such tools will facilitate studies aimed at understanding the prevalence and natural history of HHL, identifying the specific etiologies responsible for the disease in each patient, and eventually validating therapeutic interventions for this disorder. Below, we summarize several of the diagnostic approaches that are currently being studied in human subjects (see Fig. 3). Yet, is important to note that a controversy still exists whether HHL occurs in humans. Further comparisons between animal models and humans, and larger reference samples from humans will be necessary to establish strong and reliable diagnostic tools. For additional details and discussion of human auditory testing approaches with respect to HHL, see also other recent reviews (Bharadwaj et al. 2014; Plack et al. 2016; Kobel et al. 2017).

\section{ABR Measurements}

The most frequently applied tests for HHL are based on ABR recordings and electrocochleograms, with analysis of specific features of the

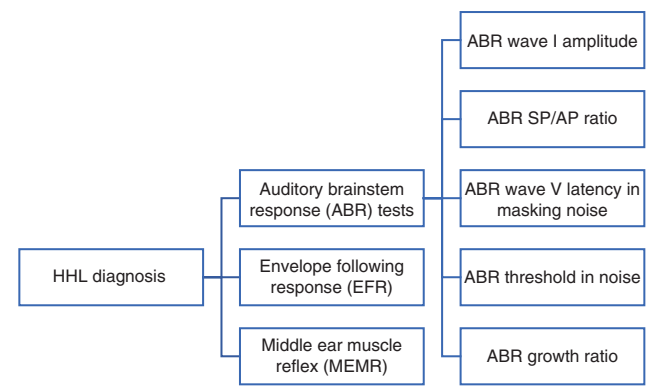

Figure 3. Noninvasive diagnosis of hidden hearing loss (HHL) in rodents and humans. Auditory brainstem response $(\mathrm{ABR})$, envelope following response (EFR), and middle ear muscle reflex (MEMR) recordings are the primary assays for HHL diagnosis. Alterations in the pattern of $A B R$ traces can be used for differential diagnosis of HHL, including peak I amplitude, summating potential (SP)/ABR peak I (AP) ratio, peak $\mathrm{V}$ latency in masking noise, threshold in noise, and slope of the sound intensity to peak I amplitude relationship.

waveforms. It has been well documented in animal models that HHL can be diagnosed by a characteristic reduction in ABR peak I amplitudes in the absence of ABR threshold or latency changes (for review, see Hickox et al. 2017). Importantly, the degree of peak I amplitude reduction correlates well with the degree of cochlear synaptopathy (Kujawa and Liberman 2009; Sergeyenko et al. 2013; Wan et al. 2014). Interestingly, mouse studies indicate that demyelination-related HHL has the additional phenotype of increased ABR peak I latency (Wan and Corfas 2017). Similarly, in humans, both aging and noise exposure have been associated with reduction of ABR peak I suprathreshold amplitudes in the absence of threshold changes (Konrad-Martin et al. 2012; Stamper and Johnson 2015). However, unlike in animal models, ABR peak I amplitudes recorded from human subjects are much smaller and more variable, limiting their clinical application for routine HHL diagnosis in individual patients (Beattie 1988; Lauter and Loomis 1988; Trune et al. 1988).

Several studies have used alternative measurements of $\mathrm{ABRs}$ or electrocochleography in an attempt to more accurately evaluate $\mathrm{AN}$ activity, particularly in humans, to relate changes in these measurements with performance on au- 
ditory tasks that rely on precise neural coding of sound. For example, the ratio between ABR peak I (AP) and SP amplitudes (AP/SP ratio) correlates with performance in a test for word comprehension in noise and self-reporting of noise exposure (Liberman et al. 2016). Similarly, latencies of peak $\mathrm{V}$, which is generated by processing in the auditory midbrain, show lower degrees of change in background noise in subjects with poorer abilities in binaural discrimination tasks (Mehraei et al. 2016), consistent with modeling predictions for loss of a subset of AN fibers (Verhulst et al. 2013). Comparable changes were also identified in mice exposed to TTS-level noise that induced ABR peak I amplitude changes and loss of IHC synapses, suggesting that ABR peak $\mathrm{V}$ latencies in a masking noise may be useful in assessing HHL in humans (Mehraei et al. 2016). Finally, a number of modeling studies have been used to simulate various cochlear hearing defects, including HHL, to better predict how various aspects of auditory waveforms will behave in response to different stimulus conditions, including pure tone thresholds in noisy backgrounds (Ridley et al. 2018) and by suprathreshold sounds (Verhulst et al. 2016). Further model validation in animals with experimentally induced HHL may lead to more precise test approaches in human, including the ability to isolate synaptopathic effects from more overt hearing loss.

\section{Envelope Following Responses}

Envelope following responses (EFRs), also called frequency following responses (FFRs), are farfield responses to AM tones that reflect neural activity at multiple locations along the auditory pathway, with relative responsiveness dependent on the AM frequency (Kuwada et al. 2002; Krishnan 2006). The AM tones are sinusoidal and continuous rather than transient as those used in ABR evaluations, and deficits in EFRs have been correlated with reduced signal detection in noise (Dimitrijevic et al. 2004) and in other listening tasks that require detection of timing cues (Ruggles et al. 2011; Bharadwaj et al. 2015). Recent animal studies indicated that declines in EFR responses to modulation frequencies near $1 \mathrm{kHz}$ correlate well with synaptic loss and HHL induced by TTS noise and by aging (Shaheen et al. 2015; Parthasarathy and Kujawa 2018). Similarly, in a recent study of humans with normal hearing thresholds, control subjects had better EFRs to a $5 \mathrm{kHz}, 85 \mathrm{~Hz}$ AM tone in background noise than subjects with suspected HHL, whose EFRs were reduced by the noise (Paul et al. 2017). Furthermore, subjects with prior recreational noise exposure appear to have reduced EFR activity compared with control subjects without noise exposure but similar hearing thresholds (Plack et al. 2014). These comparative human and animal studies support the use of EFR as an assay for cochlear synaptopathy and HHL.

\section{Middle Ear Muscle Reflex}

Low SR ANs, which are preferentially affected during cochlear synaptopathy, are also required for the middle ear muscle reflex (MEMR) (Liberman and Kiang 1984; Kobler et al. 1992). The MEMR can reduce the sound-evoked excitation of IHCs by increasing the impedance of the middle ear, thus acting as a signal attenuator to protect the cochlea from damaging sounds. MEMR is measured by monitoring the changes in sound pressure in the ear canal ipsilateral to a probe tone while eliciting the MEMR with a sound in either the ipsilateral or contralateral ear. In mouse models of HHL, elevation of MEMR threshold and reduction in suprathreshold MEMR reflex strength are correlated well with synaptopathy (Valero et al. 2016, 2018). In human subjects with tinnitus and normal audiological thresholds, the presence of HHL was suspected based on their significantly weaker MEMR responses relative to control subjects without tinnitus (Wojtczak et al. 2017). Emerging evidence suggests that MEMR may be more sensitive than the suprathreshold amplitude of ABR peak I as an indicator of moderate synaptopathy (Valero et al. 2018).

\section{POTENTIAL TREATMENTS OF HIDDEN HEARING LOSS}

Based on the increasing knowledge of mechanisms that underlie HHL, a number of potential 
D.C. Kohrman et al.

therapeutic approaches have been proposed and/or tested. To date, these have been based on strategies to repair lost IHC-SGN synapses and to augment efferent feedback responses that offer protection from noise trauma.

\section{Neurotrophins as Potential Therapies for Noise-Induced HHL}

There is increasing evidence that the neurotrophins, in particular neurotrophin 3 (NT-3), might have the ability to induce IHC synapse regeneration after HHL-inducing noise exposure (Wan et al. 2014; Cunningham and Tucci 2015). We have shown that the levels of NT-3 expression by cochlear supporting cells regulate the density of IHC synapses during cochlear maturation (Wan et al. 2014). Specifically, NT-3 overexpression in supporting cells results in higher synapse density in the cochlear base and higher auditory sensitivity in the corresponding high frequencies. Correspondingly, reductions in NT-3 expression by supporting cells at early postnatal ages results in decreased IHC synapse density in the cochlear base and a mild highfrequency hearing loss. Most relevant to HHL therapeutics, in this study we showed that NT-3 overexpression in supporting cells does not prevent the synaptopathy and TTS elicited by an HHL-inducing exposure, but IHC synapses and ABR peak I amplitudes recover within 2 weeks after the noise, consistent with NT-3 inducing synaptic regeneration. More recent studies have shown that round window delivery of either NT-3 (Suzuki et al. 2016) or NT-3 plus BDNF (Sly et al. 2016) within 24 hours following noise exposure have the same effects as transgenic NT-3 overexpression. The observation that the neurotrophin treatment worked both in mice (Suzuki et al. 2016) and guinea pigs (Sly et al. 2016) strongly supports the potential efficacy of NT-3 as a therapeutic for HHL (Fig. 4).

\section{Modulation of Efferent Feedback}

Olivocochlear efferent fibers originating in the auditory brainstem innervate the cochlea and provide feedback control of cochlear activity by the central nervous system (CNS) (Fuchs and
Lauer 2018). Lateral olivocochlear (LOC) efferent fibers synapse with the SGN terminals near IHCs, whereas medial olivocochlear (MOC) efferent fibers target OHCs (Frank and Goodrich 2018). Acetylcholine released by MOC neurons bind and activate $\mathrm{OHC}$ nicotinic acetylcholine receptors (nAChRs) comprised of the $\alpha 9 / \alpha 10$ subunits. Activation of these receptors decrease cochlear amplification. Signaling through LOC alters AN response properties and works in part through dopaminergic signaling (Guinan 2018). A number of studies have implicated both MOC and LOC efferents in cochlear protection from noise damage (for review, see Le Prell et al. 2003; Fuente 2015). Although the majority of these studies evaluated protection from intense noise exposures that result in PTS, several recent studies have evaluated the involvement of efferent responses during aging and in response to moderate noise exposures relevant to HHL.

The Liberman laboratory used a surgical ablation approach in mice to show the importance of MOC efferents for hearing protection from an extended exposure to moderate noise ( $84 \mathrm{~dB}$ for 1 week) (Maison et al. 2013). Specifically, they determined that mice with the selective MOC lesion show larger ABR peak I amplitude declines along with greater decreases in synapses than those with intact MOC efferents. A separate study showed that a lesion that removes $\sim 50 \%$ of both MOC and LOC fibers results in accelerated age-related HHL and IHC synapse loss in the absence of overt noise exposure (Liberman et al. 2014). Evaluation of innervation in the surgically treated mice suggested that MOC efferents are most important for synaptic protection in the apical half (lower frequencies) of the cochlea, whereas LOC efferent affects predominately the basal half (higher frequencies). More recently, the Gomez-Casati laboratory explored the role of efferents in noise protection by modulating MOC responses in OHCs using mice carrying either a knockout $(\mathrm{KO})$ allele of the $\mathrm{OHC} \alpha 9 \mathrm{nAChR}$ or a knockin (KI) allele of the receptor that increases its activity (Boero et al. 2018). They reported that, as expected, wild-type mice show HHL and synaptopathy 1 week after exposure to a TTS-type noise $(100 \mathrm{~dB}$ for 1 hour). In contrast, $\mathrm{KO}$ mice with loss of $\mathrm{OHC}$ 
A
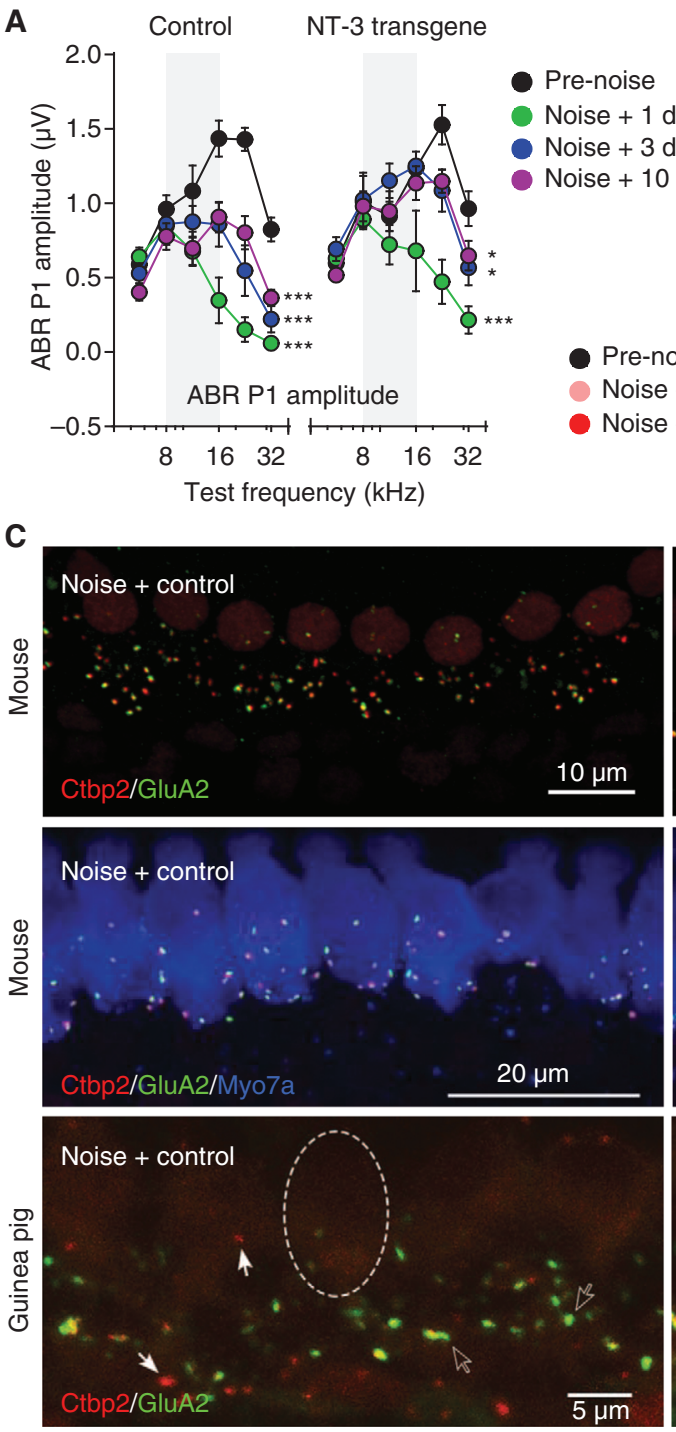

B

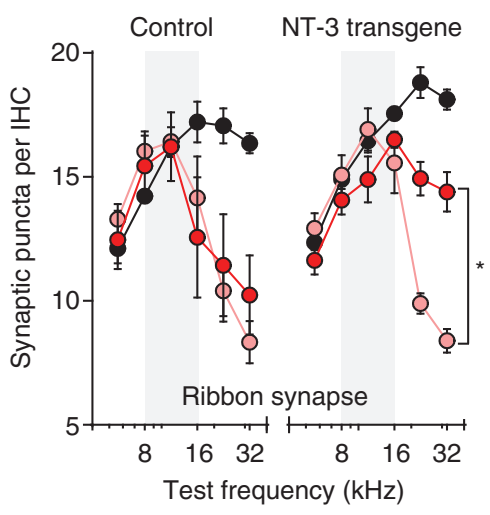

Hidden Hearing Loss

- Pre-noise

Noise $+2 \mathrm{~h}$

Noise $+14 d$
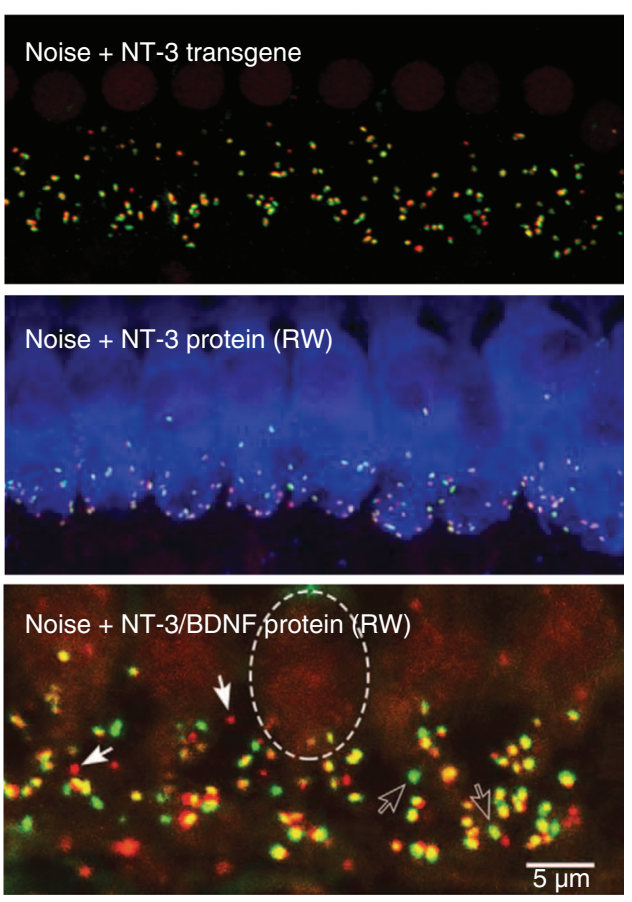

Figure 4. Neurotrophin 3 (NT-3) as a potential therapeutic for treatment of hidden hearing loss (HHL). (A) NT-3 transgenic overexpression in adult mouse cochlea promotes recovery of auditory brainstem response (ABR) peak 1 amplitudes after an HHL-inducing noise exposure (8-16 kHz, $100 \mathrm{~dB}, 2$ hours). (B) NT-3 transgenic overexpression promotes synaptic regeneration after noise exposure. $(C)$ Examples of synaptic immunostainings showing NT-3 transgene or protein promotes synaptic regeneration in both mouse and guinea pig exposed to noise. RW, Round window; inner hair cell (IHC) nucleus, dashed oval; glutamate receptors, black arrows; CtBP2-containing ribbons, white arrows. (Figure panels created from data in Wan et al. 2014, Sly et al. 2016, and Suzuki et al. 2016.)

cholinergic function develop PTS under these conditions, whereas KI mice with enhanced nAChR function do not show signs of HHL. Together, these studies suggest that augmentation of efferent signaling may be a potential strategy for minimizing both HHL resulting from mod- erate noise exposures, as well as PTS in response to more damaging noise (Maison et al. 2002; Taranda et al. 2009). However, the possibility that the transient MOC connections with IHC that occur during development (Glowatzki and Fuchs 2000; Katz et al. 2004) contribute to these 
D.C. Kohrman et al.

observations cannot be ruled out. Because LOC effects on IHC-SGN synaptic connections may operate via dopaminergic-mediated mechanisms (Ruel et al. 2001, 2007), it has been speculated that dopaminergic agonists might impact HHL. Along similar lines, NMDA glutamate receptors are expressed by AN fibers and NMDA receptor antagonists have been shown to block AN excitotoxicity (Pujol et al. 1993). Accordingly, a recent report indicated that delivery of the NMDA receptor antagonist esketamine (AM101) following noise exposure reduces HHL, although postsynaptic integrity was not evaluated in this study (Bing et al. 2015).

\section{CONCLUDING REMARKS}

The recent increased awareness of $\mathrm{HHL}$, along with the evidence that synaptopathy is a contributor to noise-induced and age-related hearing loss (Kujawa and Liberman 2009, 2015; Sergeyenko et al. 2013), has created considerable interest among auditory researchers and clinicians. So much so that the terms synaptopathy and HHL sometimes are being used interchangeably. In this review, we have attempted to clarify that other mechanisms in addition to cochlear synaptopathy may also contribute to the pathogenesis of HHL. We believe this information is particularly important when considering how to study HHL in human subjects and will impact both diagnosis and future treatment. For example, detecting reductions in amplitudes of the auditory responses does not necessarily mean the presence of synaptopathy; this finding is also consistent with myelin dysfunction. As of today, the only way to determine the presence of synaptopathy is by histological methods. Ideally, more effective diagnostic tools that distinguish between the different etiologies of HHL in each patient will permit clinicians to define which cochlear component needs to be treated, the synapse, myelin, or hair cells.

The rapid progress in the understanding of the cellular and molecular mechanisms of HHL highlights the possibility that treatments for this pervasive disorder will be available in the foreseeable future. This is important because the disruption in hearing that occurs in HHL is not well treated with current hearing aid and cochlear implant technologies, which principally address deficits in auditory thresholds. There is also a growing sense that HHL can lead to the development of tinnitus (Schaette and McAlpine 2011; Epp et al. 2012) and can contribute to the acceleration of age-related hearing loss (Kujawa and Liberman 2006, 2009; Viana et al. 2015; Wu et al. 2018). Thus, finding treatments for HHL could have impact on other prevalent hearing disorders. Furthermore, because hearing loss is a significant risk factor for cognitive decline and dementia (Livingston et al. 2017; Loughrey et al. 2018), timely management of HHL may reduce the incidence of both permanent hearing loss and dementia in the elderly population.

\section{ACKNOWLEDGMENTS}

This work is supported by National Institutes of Health/National Institute on Deafness and Other Communication Disorders (NIH/NIDCD) R01DC004820 (G.C.), the Lynn and Ruth Townsend Endowed Chair of Communication Disorders (G.C.), the Margaret G. Bertsch Endowed Research Fund (D.C.K.), and National Science Foundation Grant NSFC \#31771153 (G.W.).

\section{REFERENCES}

* Reference is also in this collection.

Alvord LS. 1983. Cochlear dysfunction in "normal-hearing" patients with history of noise exposure. Ear Hear 4: 247 250. doi:10.1097/00003446-198309000-00005

Beattie RC. 1988. Interaction of click polarity, stimulus level, and repetition rate on the auditory brainstem response. Scand Audiol 17: 99-109. doi:10.3109/010503988090 70698

Bharadwaj HM, Verhulst S, Shaheen L, Liberman MC, Shinn-Cunningham BG. 2014. Cochlear neuropathy and the coding of supra-threshold sound. Front Syst Neurosci 8: 26. doi:10.3389/fnsys.2014.00026

Bharadwaj HM, Masud S, Mehraei G, Verhulst S, ShinnCunningham BG. 2015. Individual differences reveal correlates of hidden hearing deficits. J Neurosci 35: 21612172. doi:10.1523/jneurosci.3915-14.2015

Bing D, Lee SC, Campanelli D, Xiong H, Matsumoto M, Panford-Walsh R, Wolpert S, Praetorius M, Zimmermann U, Chu H, et al. 2015. Cochlear NMDA receptors as a therapeutic target of noise-induced tinnitus. Cell Physiol Biochem 35: 1905-1923. doi:10.1159/000374000 
Boero LE, Castagna VC, Di Guilmi MN, Goutman JD, Elgoyhen AB, Gómez-Casati ME. 2018. Enhancement of the medial olivocochlear system prevents hidden hearing loss. J Neurosci 38: 7440-7451. doi:10.1523/jneurosci. 0363-18.2018

Bressler S, Goldberg H, Shinn-Cunningham B. 2017. Sensory coding and cognitive processing of sound in Veterans with blast exposure. Hear Res 349: 98-110. doi: 10.1016/j.heares.2016.10.018

Chermak GD, Musiek FE. 1997. Central auditory processing disorders: New perspectives. Singular, San Diego.

Choi JE, Seok JM, Ahn J, Ji YS, Lee KM, Hong SH, Choi BO, Moon IJ. 2018. Hidden hearing loss in patients with Charcot-Marie-Tooth disease type 1A. Sci Rep 8: 10335. doi:10.1038/s41598-018-28501-y

Clinard CG, Tremblay KL. 2013. Aging degrades the neural encoding of simple and complex sounds in the human brainstem. J Am Acad Audiol 24: 590-599; quiz 643-594. doi:10.3766/jaaa.24.7.7

Costalupes JA, Young ED, Gibson DJ. 1984. Effects of continuous noise backgrounds on rate response of auditory nerve fibers in cat. J Neurophysiol 51: 1326-1344. doi: 10.1152/jn.1984.51.6.1326

Cunningham LL, Tucci DL. 2015. Restoring synaptic connections in the inner ear after noise damage. N Engl J Med 372: 181-182. doi:10.1056/NEJMcibr1413201

Dimitrijevic A, John MS, Picton TW. 2004. Auditory steadystate responses and word recognition scores in normalhearing and hearing-impaired adults. Ear Hear 25: 6884. doi:10.1097/01.AUD.0000111545.71693.48

Duan M, Agerman K, Ernfors P, Canlon B. 2000. Complementary roles of neurotrophin 3 and a $N$-methyl-D-aspartate antagonist in the protection of noise and aminoglycoside-induced ototoxicity. Proc Natl Acad Sci 97: 7597-7602. doi:10.1073/pnas.97.13.7597

Dubno JR, Dirks DD, Morgan DE. 1984. Effects of age and mild hearing loss on speech recognition in noise. J Acoust Soc Am 76: 87-96. doi:10.1121/1.391011

Epp B, Hots J, Verhey JL, Schaette R. 2012. Increased intensity discrimination thresholds in tinnitus subjects with a normal audiogram. J Acoust Soc Am 132: EL196-EL201. doi:10.1121/1.4740462

Fernandez KA, Jeffers PWC, Lall K, Liberman MC, Kujawa SG. 2015. Aging after noise exposure: Acceleration of cochlear synaptopathy in "recovered" ears. J Neurosci 35: 7509-7520. doi:10.1523/jneurosci.5138-14.2015

Frank MM, Goodrich LV. 2018. Talking back: Development of the olivocochlear efferent system. Wiley Interdiscip Rev Dev Biol 7: e324. doi:10.1002/wdev.324

Frisina DR, Frisina RD. 1997. Speech recognition in noise and presbycusis: Relations to possible neural mechanisms. Hear Res 106: 95-104. doi:10.1016/S0378-5955 (97)00006-3

Frisina RD, Karcich KJ, Tracy TC, Sullivan DM, Walton JP, Colombo J. 1996. Preservation of amplitude modulation coding in the presence of background noise by chinchilla auditory-nerve fibers. J Acoust Soc Am 99: 475-490. doi:10.1121/1.414559

* Fuchs PA, Lauer AM. 2018. Efferent inhibition of the cochlea. Cold Spring Harb Perspect Med doi:10.1101/ cshperspect.a033530
Fuente A. 2015. The olivocochlear system and protection from acoustic trauma: A mini literature review. Front Syst Neurosci 9: 94. doi:10.3389/fnsys.2015.00094

Fulbright ANC, Le Prell CG, Griffiths SK, Lobarinas E. 2017. Effects of recreational noise on threshold and suprathreshold measures of auditory function. Semin Hear 38: 298-318. doi:10.1055/s-0037-1606325

Furman AC, Kujawa SG, Liberman MC. 2013. Noise-induced cochlear neuropathy is selective for fibers with low spontaneous rates. J Neurophysiol 110: 577-586. doi:10.1152/jn.00164.2013

Glowatzki E, Fuchs PA. 2000. Cholinergic synaptic inhibition of inner hair cells in the neonatal mammalian cochlea. Science 288: 2366-2368. doi:10.1126/science.288. 5475.2366

Gordon-Salant S. 2005. Hearing loss and aging: New research findings and clinical implications. J Rehabil Res Dev 42: 9-24. doi:10.1682/JRRD.2005.01.0006

Grinn SK, Wiseman KB, Baker JA, Le Prell CG. 2017. Hidden hearing loss? No effect of common recreational noise exposure on cochlear nerve response amplitude in humans. Front Neurosci 11: 465. doi:10.3389/fnins. 2017.00465

Grose JH, Mamo SK. 2010. Processing of temporal fine structure as a function of age. Ear Hear 31: 755-760. doi:10.1097/AUD.0b013e3181e627e7

Grose JH, Buss E, Hall JW. 2017. Loud music exposure and cochlear synaptopathy in young adults: Isolated auditory brainstem response effects but no perceptual consequences. Trends Hear 21: 2331216517737417.

Guest H, Munro KJ, Prendergast G, Millman RE, Plack CJ. 2018. Impaired speech perception in noise with a normal audiogram: No evidence for cochlear synaptopathy and no relation to lifetime noise exposure. Hear Res 364: 142 151. doi:10.1016/j.heares.2018.03.008

Guinan JJ Jr. 2018. Olivocochlear efferents: Their action, effects, measurement and uses, and the impact of the new conception of cochlear mechanical responses. Hear Res 362: 38-47. doi:10.1016/j.heares.2017.12.012

Halpin C, Thornton A, Hasso M. 1994. Low-frequency sensorineural loss: Clinical evaluation and implications for hearing aid fitting. Ear Hear 15: 71-81. doi:10.1097/ 00003446-199402000-00008

Harris KC, Dubno JR. 2017. Age-related deficits in auditory temporal processing: Unique contributions of neural dyssynchrony and slowed neuronal processing. Neurobiol Aging 53: 150-158. doi:10.1016/j.neurobiolaging.2017. 01.008

Hickman TT, Smalt C, Bobrow J, Quatieri T, Liberman MC. 2018. Blast-induced cochlear synaptopathy in chinchillas. Sci Rep 8: 10740. doi:10.1038/s41598-018-28924-7

Hickox AE, Larsen E, Heinz MG, Shinobu L, Whitton JP. 2017. Translational issues in cochlear synaptopathy. Hear Res 349: 164-171. doi:10.1016/j.heares.2016.12.010

Hoben R, Easow G, Pevzner S, Parker MA. 2017. Outer hair cell and auditory nerve function in speech recognition in quiet and in background noise. Front Neurosci 11: 157. doi:10.3389/fnins.2017.00157

Hong J, Chen Y, Zhang Y, Li J, Ren L, Yang L, Shi L, Li A, Zhang T, Li H, et al. 2018. $N$-methyl-D-aspartate receptors involvement in the gentamicin-induced hearing loss and 
D.C. Kohrman et al.

pathological changes of ribbon synapse in the mouse cochlear inner hair cells. Neural Plast 2018: 3989201.

Hossain WA, Antic SD, Yang Y, Rasband MN, Morest DK. 2005. Where is the spike generator of the cochlear nerve? Voltage-gated sodium channels in the mouse cochlea. $J$ Neurosci 25: 6857-6868. doi:10.1523/jneurosci.0123-05. 2005

Joris PX, Smith PH, Yin TC. 1994. Enhancement of neural synchronization in the anteroventral cochlear nucleus. II: Responses in the tuning curve tail. J Neurophysiol 71: 1037-1051. doi:10.1152/jn.1994.71.3.1037

Katz E, Elgoyhen AB, Gomez-Casati ME, Knipper M, Vetter DE, Fuchs PA, Glowatzki E. 2004. Developmental regulation of nicotinic synapses on cochlear inner hair cells. J Neurosci 24: 7814-7820. doi:10.1523/jneurosci.210204.2004

Kim KX, Rutherford MA. 2016. Maturation of $\mathrm{Na}_{\mathrm{V}}$ and $\mathrm{K}_{\mathrm{V}}$ channel topographies in the auditory nerve spike initiator before and after developmental onset of hearing function. J Neurosci 36: 2111-2118. doi:10.1523/jneurosci.343715.2016

King A, Hopkins K, Plack CJ. 2014. The effects of age and hearing loss on interaural phase difference discrimination. J Acoust Soc Am 135: 342-351. doi:10.1121/1. 4838995

Kluk K, Prendergast G, Guest H, Munro KJ, Léger A, Hall DA, Heinz M, Plack CJ. 2016. No evidence for hidden hearing loss due to noise exposure in young adults with a normal audiogram. J Acoust Soc Am 140: 3152-3152. doi:10.1121/1.4969885

Kobel M, Le Prell CG, Liu J, Hawks JW, Bao J. 2017. Noiseinduced cochlear synaptopathy: Past findings and future studies. Hear Res 349: 148-154. doi:10.1016/j.heares. 2016.12.008

Kobler JB, Guinan JJ Jr, Vacher SR, Norris BE. 1992. Acoustic reflex frequency selectivity in single stapedius motoneurons of the cat. J Neurophysiol 68: 807-817. doi: 10.1152/jn. 1992.68.3.807

Konrad-Martin D, Dille MF, McMillan G, Griest S, McDermott D, Fausti SA, Austin DF. 2012. Age-related changes in the auditory brainstem response. J Am Acad Audiol 23: 18-35; quiz 74-15. doi:10.3766/jaaa.23.1.3

Krishnan A. 2006. Frequency-following response. Lippincott Williams \& Wilkins, Philadelphia.

Kujala T, Shtyrov Y, Winkler I, Saher M, Tervaniemi M, Sallinen M, Teder-Salejarvi W, Alho K, Reinikainen K, Naatanen R. 2004. Long-term exposure to noise impairs cortical sound processing and attention control. Psychophysiology 41: 875-881. doi:10.1111/j.1469-8986.2004. 00244.x

Kujawa SG, Liberman MC. 2006. Acceleration of age-related hearing loss by early noise exposure: Evidence of a misspent youth. J Neurosci 26: 2115-2123. doi:10.1523/ jneurosci.4985-05.2006

Kujawa SG, Liberman MC. 2009. Adding insult to injury: Cochlear nerve degeneration after "temporary" noiseinduced hearing loss. J Neurosci 29: 14077-14085. doi: 10.1523/jneurosci.2845-09.2009

Kujawa SG, Liberman MC. 2015. Synaptopathy in the noiseexposed and aging cochlea: Primary neural degeneration in acquired sensorineural hearing loss. Hear Res 330: 191-199. doi:10.1016/j.heares.2015.02.009
Kumar UA, Ameenudin S, Sangamanatha AV. 2012. Temporal and speech processing skills in normal hearing individuals exposed to occupational noise. Noise Health 14: 100-105.

Kuwabara S, Yuki N. 2013. Axonal Guillain-Barré syndrome: Concepts and controversies. Lancet Neurol 12: 1180-1188. doi:10.1016/S1474-4422(13)70215-1

Kuwada S, Anderson JS, Batra R, Fitzpatrick DC, Teissier N, D'Angelo WR. 2002. Sources of the scalp-recorded amplitude-modulation following response. J Am Acad Audiol 13: 188-204.

Lauter JL, Loomis RL. 1988. Individual differences in auditory electric responses: Comparisons of between-subject and within-subject variability. II: Amplitude of brainstem vertex-positive peaks. Scand Audiol 17: 87-92. doi: 10.3109/01050398809070696

Le Prell CG, Dolan DF, Schacht J, Miller JM, Lomax MI, Altschuler RA. 2003. Pathways for protection from noise induced hearing loss. Noise Health 5: 1-17.

Liberman MC, Kiang NY. 1984. Single-neuron labeling and chronic cochlear pathology. IV: Stereocilia damage and alterations in rate- and phase-level functions. Hear Res 16: 75-90. doi:10.1016/0378-5955(84)90026-1

Liberman MC, Kujawa SG. 2017. Cochlear synaptopathy in acquired sensorineural hearing loss: Manifestations and mechanisms. Hear Res 349: 138-147. doi:10.1016/j. heares.2017.01.003

Liberman LD, Liberman MC. 2015. Dynamics of cochlear synaptopathy after acoustic overexposure. J Assoc Res Otolaryngol 16: 205-219. doi:10.1007/s10162-015-0510-3

Liberman MC, Liberman LD, Maison SF. 2014. Efferent feedback slows cochlear aging. J Neurosci 34: 45994607. doi:10.1523/jneurosci.4923-13.2014

Liberman MC, Epstein MJ, Cleveland SS, Wang H, Maison SF. 2016. Toward a differential diagnosis of hidden hearing loss in humans. PLOS ONE 11: e0162726. doi:10.1371/ journal.pone. 0162726

Lin HW, Furman AC, Kujawa SG, Liberman MC. 2011. Primary neural degeneration in the Guinea pig cochlea after reversible noise-induced threshold shift. J Assoc Res Otolaryngol 12: 605-616. doi:10.1007/s10162-011-0277-0

Liu L, Wang H, Shi L, Almuklass A, He T, Aiken S, Bance M, Yin S, Wang J. 2012. Silent damage of noise on cochlear afferent innervation in guinea pigs and the impact on temporal processing. PLoS ONE 7: e49550. doi:10.1371/ journal.pone.0049550

Liu K, Chen D, Guo W, Yu N, Wang X, Ji F, Hou Z, Yang WY, Yang S. 2015. Spontaneous and partial repair of ribbon synapse in cochlear inner hair cells after ototoxic withdrawal. Mol Neurobiol 52: 1680-1689. doi:10.1007/ s12035-014-8951-y

Livingston G, Sommerlad A, Orgeta V, Costafreda SG, Huntley J, Ames D, Ballard C, Banerjee S, Burns A, CohenMansfield J, et al. 2017. Dementia prevention, intervention, and care. Lancet 390: 2673-2734. doi:10.1016/ S0140-6736(17)31363-6

Lobarinas E, Spankovich C, Le Prell CG. 2017. Evidence of "hidden hearing loss" following noise exposures that produce robust TTS and ABR wave-I amplitude reductions. Hear Res 349: 155-163. doi:10.1016/j.heares.2016.12.009 
Long P, Wan G, Roberts MT, Corfas G. 2018. Myelin development, plasticity, and pathology in the auditory system. Dev Neurobiol 78: 80-92. doi:10.1002/dneu.22538

Loughrey DG, Kelly ME, Kelley GA, Brennan S, Lawlor BA. 2018. Association of age-related hearing loss with cognitive function, cognitive impairment, and dementia: A systematic review and meta-analysis. JAMA Otolaryngol Head Neck Surg 144: 115-126. doi:10.1001/jamaoto. 2017. 2513

Maison SF, Luebke AE, Liberman MC, Zuo J. 2002. Efferent protection from acoustic injury is mediated via $\alpha 9$ nicotinic acetylcholine receptors on outer hair cells. $J$ Neurosci 22: 10838-10846. doi:10.1523/jneurosci.22-2410838. 2002

Maison SF, Usubuchi H, Liberman MC. 2013. Efferent feedback minimizes cochlear neuropathy from moderate noise exposure. J Neurosci 33: 5542-5552. doi:10.1523/ jneurosci.5027-12.2013

Makary CA, Shin J, Kujawa SG, Liberman MC, Merchant SN. 2011. Age-related primary cochlear neuronal degeneration in human temporal bones. J Assoc Res Otolaryngol 12: 711-717. doi:10.1007/s10162-011-0283-2

Marmel F, Linley D, Carlyon RP, Gockel HE, Hopkins K, Plack CJ. 2013. Subcortical neural synchrony and absolute thresholds predict frequency discrimination independently. J Assoc Res Otolaryngol 14: 757-766. doi: 10.1007/s10162-013-0402-3

Mehraei G, Hickox AE, Bharadwaj HM, Goldberg H, Verhulst S, Liberman MC, Shinn-Cunningham BG. 2016. Auditory brainstem response latency in noise as a marker of cochlear synaptopathy. J Neurosci 36: 3755-3764. doi:10.1523/jneurosci.4460-15.2016

Mulders WH, Chin AMIL, Robertson D. 2018. Persistent hair cell malfunction contributes to hidden hearing loss. Hear Res 361: 45-51. doi:10.1016/j.heares.2018.02.001

Muniak MA, Ayeni FE, Ryugo DK. 2018. Hidden hearing loss and endbulbs of Held: Evidence for central pathology before detection of ABR threshold increases. Hear Res 364: 104-117. doi:10.1016/j.heares.2018.03.021

Niwa K, Mizutari K, Matsui T, Kurioka T, Matsunobu T, Kawauchi S, Satoh Y, Sato S, Shiotani A, Kobayashi Y. 2016. Pathophysiology of the inner ear after blast injury caused by laser-induced shock wave. Sci Rep 6: 31754 . doi:10.1038/srep31754

Oishi N, Duscha S, Boukari H, Meyer M, Xie J, Wei G, Schrepfer T, Roschitzki B, Boettger EC, Schacht J. 2015. XBP1 mitigates aminoglycoside-induced endoplasmic reticulum stress and neuronal cell death. Cell Death Dis 6 : e1763. doi:10.1038/cddis.2015.108

Olusanya BO, Neumann KJ, Saunders JE. 2014. The global burden of disabling hearing impairment: A call to action Bull World Health Organ 92: 367-373. doi:10.2471/BLT. 13.128728

Panganiban CH, Barth JL, Darbelli L, Xing Y, Zhang J, Li H, Noble KV, Liu T, Brown LN, Schulte BA, et al. 2018. Noise-induced dysregulation of Quaking RNA binding proteins contributes to auditory nerve demyelination and hearing loss. J Neurosci 38: 2551-2568. doi: 10.1523/ jneurosci.2487-17.2018

Parthasarathy A, Kujawa SG. 2018. Synaptopathy in the aging cochlea: Characterizing early-neural deficits in audi- tory temporal envelope processing. J Neurosci 38: 71087119. doi:10.1523/jneurosci.3240-17.2018

Paul BT, Bruce IC, Roberts LE. 2017. Evidence that hidden hearing loss underlies amplitude modulation encoding deficits in individuals with and without tinnitus. Hear Res 344: 170-182. doi:10.1016/j.heares.2016.11.010

Pichora-Fuller MK, Souza PE. 2003. Effects of aging on auditory processing of speech. Int J Audiol 42: 2S11-2S16. doi:10.3109/14992020309074638

Plack CJ, Barker D, Prendergast G. 2014. Perceptual consequences of "hidden" hearing loss. Trends Hear 18. doi:10.1177/2331216514550621

Plack CJ, Léger A, Prendergast G, Kluk K, Guest H, Munro KJ. 2016. Toward a diagnostic test for hidden hearing loss. Trends Hear 20: 2331216516657466 . doi:10.1177/ 2331216516657466

Prendergast G, Guest H, Munro KJ, Kluk K, Léger A, Hall DA, Heinz MG, Plack CJ. 2017a. Effects of noise exposure on young adults with normal audiograms. I: Electrophysiology. Hear Res 344: 68-81. doi:10.1016/j.heares.2016. 10.028

Prendergast G, Millman RE, Guest H, Munro KJ, Kluk K, Dewey RS, Hall DA, Heinz MG, Plack CJ. 2017b. Effects of noise exposure on young adults with normal audiograms. II: Behavioral measures. Hear Res 356: 74-86. doi:10.1016/j.heares.2017.10.007

Pujol R, Puel JL, Gervais d'Aldin C, Eybalin M. 1993. Pathophysiology of the glutamatergic synapses in the cochlea. Acta Otolaryngol 113: 330-334. doi:10.3109/000164893 09135819

Rajan R, Cainer KE. 2008. Ageing without hearing loss or cognitive impairment causes a decrease in speech intelligibility only in informational maskers. Neuroscience 154: 784-795. doi:10.1016/j.neuroscience.2008.03.067

Rance G. 2005. Auditory neuropathy/dys-synchrony and its perceptual consequences. Trends Amplif 9: 1-43. doi: $10.1177 / 108471380500900102$

Rance G, Starr A. 2015. Pathophysiological mechanisms and functional hearing consequences of auditory neuropathy. Brain 138: 3141-3158. doi:10.1093/brain/awv270

Rance G, Ryan MM, Bayliss K, Gill K, O'Sullivan C, Whitechurch M. 2012. Auditory function in children with Charcot-Marie-Tooth disease. Brain 135: 1412-1422. doi:10.1093/brain/aws085

Rasband MN, Peles E. 2015. The Nodes of Ranvier: Molecular assembly and maintenance. Cold Spring Harb Perspect Biol 8: a020495. doi:10.1101/cshperspect.a020495

Reijntjes DOJ, Pyott SJ. 2016. The afferent signaling complex: Regulation of type I spiral ganglion neuron responses in the auditory periphery. Hear Res 336: 1-16. doi:10.1016/j.heares.2016.03.011

Rhode WS, Greenberg S. 1994. Encoding of amplitude modulation in the cochlear nucleus of the cat. J Neurophysiol 71: 1797-1825. doi:10.1152/jn.1994.71.5.1797

Ridley CL, Kopun JG, Neely ST, Gorga MP, Rasetshwane DM. 2018. Using thresholds in noise to identify hidden hearing loss in humans. Ear Hear 39: 829-844. doi: 10.1097/AUD.0000000000000543

Rossor AM, Polke JM, Houlden H, Reilly MM. 2013. Clinical implications of genetic advances in Charcot-Marie- 
D.C. Kohrman et al.

Tooth disease. Nat Rev Neurol 9: 562-571. doi:10.1038/ nrneurol. 2013.179

Ruan Q, Ao H, He J, Chen Z, Yu Z, Zhang R, Wang J, Yin S. 2014. Topographic and quantitative evaluation of gentamicin-induced damage to peripheral innervation of mouse cochleae. Neurotoxicology 40: 86-96. doi: 10. 1016/j.neuro.2013.11.002

Ruel J, Nouvian R, Gervais d'Aldin C, Pujol R, Eybalin M, Puel JL. 2001. Dopamine inhibition of auditory nerve activity in the adult mammalian cochlea. Eur J Neurosci 14: 977-986. doi:10.1046/j.0953-816x.2001.01721.x

Ruel J, Wang J, Rebillard G, Eybalin M, Lloyd R, Pujol R, Puel JL. 2007. Physiology, pharmacology and plasticity at the inner hair cell synaptic complex. Hear Res 227: 19-27. doi:10.1016/j.heares.2006.08.017

Ruggles D, Bharadwaj H, Shinn-Cunningham BG. 2011. Normal hearing is not enough to guarantee robust encoding of suprathreshold features important in everyday communication. Proc Natl Acad Sci 108: 15516-15521. doi:10.1073/pnas.1108912108

Rutherford MA, Chapochnikov NM, Moser T. 2012. Spike encoding of neurotransmitter release timing by spiral ganglion neurons of the cochlea. J Neurosci 32: 47734789. doi:10.1523/jneurosci.4511-11.2012

Schacht J, Talaska AE, Rybak LP. 2012. Cisplatin and aminoglycoside antibiotics: Hearing loss and its prevention. Anat Rec (Hoboken) 295: 1837-1850. doi:10.1002/ar. 22578

Schaette R, McAlpine D. 2011. Tinnitus with a normal audiogram: Physiological evidence for hidden hearing loss and computational model. J Neurosci 31: 13452-13457. doi:10.1523/jneurosci.2156-11.2011

Schalk TB, Sachs MB. 1980. Nonlinearities in auditory-nerve fiber responses to bandlimited noise. J Acoust Soc Am 67: 903-913. doi:10.1121/1.383970

Schmiedt RA, Mills JH, Boettcher FA. 1996. Age-related loss of activity of auditory-nerve fibers. J Neurophysiol 76: 2799-2803. doi:10.1152/jn.1996.76.4.2799

Sergeyenko Y, Lall K, Liberman MC, Kujawa SG. 2013. Agerelated cochlear synaptopathy: An early-onset contributor to auditory functional decline. J Neurosci 33: 1368613694. doi:10.1523/jneurosci.1783-13.2013

Shaheen LA, Valero MD, Liberman MC. 2015. Towards a diagnosis of cochlear neuropathy with envelope following responses. J Assoc Res Otolaryngol 16: 727-745. doi: 10.1007/s10162-015-0539-3

Shi L, Liu L, He T, Guo X, Yu Z, Yin S, Wang J. 2013. Ribbon synapse plasticity in the cochleae of Guinea pigs after noise-induced silent damage. PLoS ONE 8: e81566. doi:10.1371/journal.pone.0081566

Shi L, Liu K, Wang H, Zhang Y, Hong Z, Wang M, Wang X, Jiang X, Yang S. 2015. Noise induced reversible changes of cochlear ribbon synapses contribute to temporary hearing loss in mice. Acta Otolaryngol 135: 1093-1102. doi:10.3109/00016489.2015.1061699

Shi L, Chang Y, Li X, Aiken SJ, Liu L, Wang J. 2016. Coding deficits in noise-induced hidden hearing loss may stem from incomplete repair of ribbon synapses in the cochlea. Front Neurosci 10: 231. doi:10.3389/fnins.2016.00231

Sly DJ, Campbell L, Uschakov A, Saief ST, Lam M, O’Leary SJ. 2016. Applying neurotrophins to the round window rescues auditory function and reduces inner hair cell synaptopathy after noise-induced hearing loss. Otol Neurotol 37: 1223-1230. doi:10.1097/MAO.0000000000001191

Song Q, Shen P, Li X, Shi L, Liu L, Wang J, Yu Z, Stephen K, Aiken S, Yin S, Wang J. 2016. Coding deficits in hidden hearing loss induced by noise: The nature and impacts. $\mathrm{Sc} i$ Rep 6: 25200 . doi:10.1038/srep25200

Spankovich C, Gonzalez VB, Su D, Bishop CE. 2018. Self reported hearing difficulty, tinnitus, and normal audiometric thresholds, the National Health and Nutrition Examination Survey 1999-2002. Hear Res 358: 30-36. doi:10.1016/j.heares.2017.12.001

Stamper GC, Johnson TA. 2015. Auditory function in normal-hearing, noise-exposed human ears. Ear Hear 36: 172-184. doi:10.1097/AUD.0000000000000107

Stone MA, Moore BC, Greenish H. 2008. Discrimination of envelope statistics reveals evidence of sub-clinical hearing damage in a noise-exposed population with "normal" hearing thresholds. Int J Audiol 47: 737-750. doi: 10. 1080/14992020802290543

Suzuki J, Corfas G, Liberman MC. 2016. Round-window delivery of neurotrophin 3 regenerates cochlear synapses after acoustic overexposure. Sci Rep 6: 24907. doi:10.1038/ srep24907

Tagoe T, Barker M, Jones A, Allcock N, Hamann M. 2014. Auditory nerve perinodal dysmyelination in noise-induced hearing loss. J Neurosci 34: 2684-2688. doi: 10.1523/jneurosci.3977-13.2014

Takazawa T, Ikeda K, Murata K, Kawase Y, Hirayama T, Ohtsu M, Harada H, Totani T, Sugiyama K, Kawabe K, et al. 2012. Sudden deafness and facial diplegia in Guillain-Barré syndrome: Radiological depiction of facial and acoustic nerve lesions. Intern Med 51: 2433-2437. doi:10.2169/internalmedicine.51.7737

Taranda J, Maison SF, Ballestero JA, Katz E, Savino J, Vetter DE, Boulter J, Liberman MC, Fuchs PA, Elgoyhen AB. 2009. A point mutation in the hair cell nicotinic cholinergic receptor prolongs cochlear inhibition and enhances noise protection. PLoS Biol 7: e1000018. doi:10.1371/ journal.pbio.1000018

Tremblay KL, Pinto A, Fischer ME, Klein BE, Klein R, Levy S, Tweed TS, Cruickshanks KJ. 2015. Self-reported hearing difficulties among adults with normal audiograms: The Beaver Dam Offspring Study. Ear Hear 36: e290e299. doi:10.1097/AUD.0000000000000195

Trune DR, Mitchell C, Phillips DS. 1988. The relative importance of head size, gender and age on the auditory brainstem response. Hear Res 32: 165-174. doi:10.1016/ 0378-5955(88)90088-3

Valderrama JT, Beach EF, Yeend I, Sharma M, Van Dun B, Dillon H. 2018. Effects of lifetime noise exposure on the middle-age human auditory brainstem response, tinnitus and speech-in-noise intelligibility. Hear Res 365: 36-48. doi:10.1016/j.heares.2018.06.003

Valero MD, Hancock KE, Liberman MC. 2016. The middle ear muscle reflex in the diagnosis of cochlear neuropathy. Hear Res 332: 29-38. doi:10.1016/j.heares.2015.11.005

Valero MD, Burton JA, Hauser SN, Hackett TA, Ramachandran R, Liberman MC. 2017. Noise-induced cochlear synaptopathy in rhesus monkeys (Macaca mulatta). Hear Res 353: 213-223. doi:10.1016/j.heares.2017.07.003 
Hidden Hearing Loss

Valero MD, Hancock KE, Maison SF, Liberman MC. 2018 Effects of cochlear synaptopathy on middle-ear muscle reflexes in unanesthetized mice. Hear Res 363: 109-118. doi:10.1016/j.heares.2018.03.012

Verhulst S, Bharadwaj H, Mehraei G, Shinn-Cunningham B 2013. Understanding hearing impairment through model predictions of brainstem responses. Trends Hear 19: 050182. doi:10.1177/2331216516672186

Verhulst S, Jagadeesh A, Mauermann M, Ernst F. 2016. Individual differences in auditory brainstem response wave characteristics: Relations to different aspects of peripheral hearing loss. Trends Hear 20: 2331216516672186. doi: 10.1177/2331216516672186

Viana LM, O’Malley JT, Burgess BJ, Jones DD, Oliveira CACP, Santos F, Merchant SN, Liberman LD, Liberman MC. 2015. Cochlear neuropathy in human presbycusis: Confocal analysis of hidden hearing loss in post-mortem tissue. Hear Res 327: 78-88. doi:10.1016/j.heares.2015. 04.014

Wan G, Corfas G. 2015. No longer falling on deaf ears: Mechanisms of degeneration and regeneration of cochlear ribbon synapses. Hear Res 329: 1-10. doi:10.1016/j. heares.2015.04.008

Wan G, Corfas G. 2017. Transient auditory nerve demyelination as a new mechanism for hidden hearing loss. Nat Commun 8: 14487. doi:10.1038/ncomms14487
Wan G, Gómez-Casati ME, Gigliello AR, Liberman MC, Corfas G. 2014. Neurotrophin-3 regulates ribbon synapse density in the cochlea and induces synapse regeneration after acoustic trauma. eLife 3: e03564.

Wojtczak M, Beim JA, Oxenham AJ. 2017. Weak middleear-muscle reflex in humans with noise-induced tinnitus and normal hearing may reflect cochlear synaptopathy. eNeuro 4. doi:10.1523/eneuro.0363-17.2017

Wu PZ, Liberman LD, Bennett K, de Gruttola V, O’Malley JT, Liberman MC. 2018. Primary neural degeneration in the human cochlea: Evidence for hidden hearing loss in the aging ear. Neuroscience doi:10.1016/j.neuroscience. 2018.07.053

Xing Y, Samuvel DJ, Stevens SM, Dubno JR, Schulte BA, Lang H. 2012. Age-related changes of myelin basic protein in mouse and human auditory nerve. PLOS ONE 7: e34500. doi:10.1371/journal.pone.0034500

Zheng XY, Ding DL, McFadden SL, Henderson D. 1997. Evidence that inner hair cells are the major source of cochlear summating potentials. Hear Res 113: 76-88. doi:10.1016/S0378-5955(97)00127-5

Zhou R, Assouline JG, Abbas PJ, Messing A, Gantz BJ. 1995. Anatomical and physiological measures of auditory system in mice with peripheral myelin deficiency. Hear Res 88: 87-97. doi:10.1016/0378-5955(95)00104-C 


\title{
$\&_{\mathrm{CSH}}^{\infty} \&$ Cold Spring Harbor

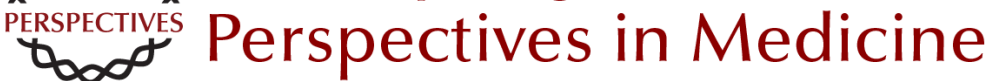

\section{Hidden Hearing Loss: A Disorder with Multiple Etiologies and Mechanisms}

\author{
David C. Kohrman, Guoqiang Wan, Luis Cassinotti and Gabriel Corfas
}

Cold Spring Harb Perspect Med 2020; doi: 10.1101/cshperspect.a035493 originally published online January 7, 2019

\section{Subject Collection Function and Dysfunction of the Cochlea}

Hidden Hearing Loss: A Disorder with Multiple

Etiologies and Mechanisms

David C. Kohrman, Guoqiang Wan, Luis Cassinotti, et al.

Hair Cell Afferent Synapses: Function and

Dysfunction

Stuart L. Johnson, Saaid Safieddine, Mirna Mustapha, et al.

Active Biomechanics of Sensory Hair Bundles Dolores Bozovic

The Tectorial Membrane: Mechanical Properties and Functions Jonathan B. Sellon, Roozbeh Ghaffari and Dennis M. Freeman

The Epidemiology of Deafness Abraham M. Sheffield and Richard J.H. Smith

Toward the Optical Cochlear Implant Tobias Dombrowski, Vladan Rankovic and Tobias Moser

Outer Hair Cells and Electromotility Jonathan Ashmore

Interactions between Macrophages and the Sensory Cells of the Inner Ear Mark E. Warchol
Development and Patterning of the Cochlea: From

Convergent Extension to Planar Polarity Mireille Montcouquiol and Matthew W. Kelley

Hair-Bundle Links: Genetics as the Gateway to Function Guy P. Richardson and Christine Petit

Aminoglycoside- and Cisplatin-Induced Ototoxicity: Mechanisms and Otoprotective Strategies

Corné J. Kros and Peter S. Steyger

Function and Dysfunction of TMC Channels in Inner Ear Hair Cells

David P. Corey, Nurunisa Akyuz and Jeffrey R. Holt

Cochlear Gene Therapy

Lawrence Lustig and Omar Akil

Age-Related Hearing Loss

Michael R. Bowl and Sally J. Dawson

Inner Ear Connexin Channels: Roles in Development and Maintenance of Cochlear

Function

Fabio Mammano

A Functional Perspective on the Evolution of the Cochlea Christine Köppl and Geoffrey A. Manley

For additional articles in this collection, see http://perspectivesinmedicine.cshlp.org/cgi/collection/ 